\title{
Recuperación y análisis documental de fondos y colecciones fotográficas: las imágenes de la Guerra de África del capitán médico Bosch Díaz
}

Recovery and documentary analysis of photographic collections: Medical Captain Bosch Díaz's pictures of war in Africa

\author{
Juan Miguel SÁnchez Vigil (1), María Olivera Zaldua (2), Juan Carlos Marcos Recio (3)
}

(1) Facultad de Ciencias de la Documentación de UCM, C/Stma Trinidad 37 28010, jmvigil@ucm.es (2) molivera@ucm.es (3) Facultad de Ciencias de la Información de UCM, Av. Complutense s/n 28040, jmarcos@ucm.

\begin{abstract}
Resumen
La recuperación de los fondos y colecciones fotográficas es una de las cuestiones pendientes de análisis en el conjunto de la documentación fotográfica. Si bien es cierto que forman parte del patrimonio cultural, no lo es menos que socialmente no tiene la misma consideración que otros documentos u objetos artísticos, por lo que no basta con las leyes generales sino que debería establecerse un protocolo oficial para su protección. Es objeto de análisis en este artículo, como paradigma de lo anteriormente expuesto, la recuperación y tratamiento documental de las fotografías de la guerra de África realizadas entre 1921 y 1925 por el capitán médico José Bosch Díaz. Se han analizado más de trescientos placas de cristal en formato $10 \times 15 \mathrm{~cm}$, documentos que muestran la vida cotidiana de los soldados en las posesiones españolas del Rif, la actividad médica en el ejército, vistas de localidades y retratos de tipos de la zona. La recuperación y análisis del corpus supone una gran contribución a la historia del ejército español y de la guerra de África, así como a la historia de la fotografía española.
\end{abstract}

Palabras clave: Patrimonio fotográfico. Documentación fotográfica. Guerra de África. Bosch Díaz, Jorge. Fotografía médica. Historia de la fotografía.

\section{Introducción}

La transversalidad de la fotografía la hace estar presente en todos los ámbitos culturales y científicos, no solo como herramienta o lenguaje en lo que se refiere a la forma de expresión, sino por sus propios contenidos. El caso que nos ocupa se relaciona con la fotografía de guerra, imágenes captadas por el capitán médico Jorge Bosch Díaz en el Rif durante la tercera década del siglo XX, periodo crítico en el que se produjeron los desastres de Annual y Monte Arruit.

La investigación que se ha llevado a cabo tiene por objeto específico analizar y difundir los fondos de Jorge Bosch Díaz con el fin de aportar nuevos datos a la historia de la guerra de África y por extensión del Ejército español, además de

\begin{abstract}
The recovery of photographic collections is an important issue pending analysis in general in regard to photographic documentation. Even though they form a part of the cultural heritage, it is also true that socially speaking they do not receive the same consideration as other documents or artistic objects, and so the general laws existing do not suffice and an official protocol should be established for their protection. To provide a model to follow regarding the foregoing, this article endeavors to analyze the recovery and documentary processing of the photographs of the War in Africa taken between 1921 and 1925 by Medical Captain José Bosch Díaz. More than three hundred $10 \times 15 \mathrm{~cm}$ photographic plates have been studied, as documents which reflect the everyday life of the soldiers stationed on the Spanish possessions of the Rif, the activity of the army doctors, pictures of the towns and portraits of the inhabitants of the area. The recovery and analysis of this corpus represents a major contribution to the history of the Spanish Army and the War in Africa, as well as the history of Spanish photography.
\end{abstract}

Keywords: Photographic heritage. Photographic documentation. War in Africa. Bosch Díaz, Jorge. Medical photography. History of photography.

la historia de la fotografía en los años indicados. Por otra parte se plantea la necesidad de establecer protocolos públicos de actuación que permitan la recuperación del patrimonio fotográfico susceptible de deterioro, pérdida o destrucción.

El fondo Bosch fue adquirido a un particular en varias compras, se hallaba disperso y sin información alguna en cuanto a la autoría. Se conservaba en las cajas originales, varias de ellas con humedad que afecta considerablemente a parte de las placas en su emulsión. Componen el conjunto 509 negativos de vidrio en formato $10 \times 15 \mathrm{~cm}$ realizados entre 1914 y 1924.

La metodología aplicada contempla varias fases de trabajo; por una parte la revisión bibliográfica sobre la guerra de África en el periodo en que 
fueron tomadas las fotografías, la elaboración de la biografía de Jorge Bosch Díaz con la documentación localizada, y la realización de una base de datos con los campos necesarios para la recuperación de información a partir de cada una de las imágenes. Después de procesar y analizar los datos se procedió a la redacción del texto y las conclusiones. A los campos generales (autor, lugar y fecha) se han añadido otros específicos (palabras clave y observaciones) con el fin de describir el contenido de cada fotografía. Finalmente se seleccionaron las ocho fotografías que ilustran el estudio.

Las fuentes generales han sido las hemerotecas digitales de la Biblioteca Nacional de España y del archivo del diario $A b c$, y las específicas el periódico La Correspondencia Militar y la Revista de Sanidad Militar. De las instituciones destacamos el Archivo General Militar de Segovia, el Centro Documental de la Memoria Histórica (Salamanca) y el Colegio de Médicos de Madrid. Para la biografía de Bosch ha sido fundamental el trabajo de Almela Cots (2015), y entre las numerosas monografías y artículos sobre la guerra de África se han seleccionado las obras de Tuñón de Lara (1984), Seco Serrano (1995) y Lorenzo Silva (20012 y 2013). En cuanto a la fotografía sobre la guerra en África se han consultado los trabajos de Gómez Barceló (2005 y 2007) y Olivera Zaldua (2014); y sobre la vida cotidiana en el Ejército, los de Castillo y Cabezón (2006).

La contextualización y valoración de la fotografía como patrimonio se ha realizado a partir del Plan Nacional de Conservación del Patrimonio Fotográfico, coordinado por Chumillas (2015) y del libro Patrimonio bibliográfico. De la visibilidad a la gestión, coordinado por Salvador (2016). Para la elaboración de la base de datos se han seguido las normas ISAD-G, la ficha de trabajo empleada por Sánchez Vigil y Olivera Zaldua (2012), y los manuales de Boadas (2001) y Valle Gastaminza (1999).

En base a los objetivos que se indican se ha revisado también bibliografía específica en relación con la metodología para el estudio de la fotografía, la producción documental, la preservación, la conservación y la representación de la información. Además de las obras citadas de Boadas y Valle Gastaminza, han sido fundamentales la monografía Lo efímero y lo perpetuo en la imagen fotográfica, ensayo en el que Boris Kossoy (2014) analiza la importancia de las fuentes, la recuperación de la información y las metodologías de trabajo; en lo que se refiere a la identificación de los documentos se ha seguido el manual de Jordi Mestre (2004) titulado Identificación y conservación de fotografías, cuyo capítulo específico "El archivo de fotografías" señala los principales problemas para abordar una colección, y en este sentido es fundamental como referente el libro $(R e)$ conocer y conservar las fotografías antiguas de Bertrand Lavédrine (2010), del que hemos obtenido información sobre los positivos monocromos en vidrio.

\section{Jorge Bosch Díaz: apunte biográfico}

Jorge Bosch Díaz nació en Cienfuegos, Cuba, el 9 de agosto de 1884, hijo del general Valeriano Bosch Sánchez y de Vicenta Serrano Aguirre. El general Bosch estuvo en Cuba antes del desastre del 98 y posteriormente en Melilla, pero su aportación al Ejército fue la reforma de la administración militar.

Jorge Bosch estudió de Medicina y Cirugía en la Universidad de Madrid, donde obtuvo el Grado en Fisioterapia el 18 de abril de 1911. Fue Presidente de la Comisión Escolar Madrileña de Sanatorios Militares entre 1909 y 1910, y trabajó por mejorar las condiciones de los soldados en Marruecos, estudiando los problemas relacionados con la tisis y la tuberculosis (Almela, 2015). Contrajo matrimonio con Angélica González Amieba (Madrid, 1885-1974) el 10 de octubre de 1911, hija del coronel de infantería Toribio González Iriarte y de Angélica Amieba Jiménez, fallecidos en diciembre de 1919 y junio de 1920 respectivamente. Su hermano fue el comandante de infantería Alfredo González Amieba (Álava, 1880-Madrid, 1926). Tuvieron dos hijos: Jorge Valerio Bosch González (Madrid, 19171996), médico casado con María Josefa Manrique Sánchez (1926-2010), y Angelina Bosch González (1919-2006)

En 1914 ganó la oposición de ingreso en la Academia Médico Militar y fue nombrado alumno de la Academia Médica Militar (Real Orden de 25 de febrero). El 1 de marzo comenzó su actividad y un mes después juró bandera en el Segundo Regimiento de Zapadores Minadores. El 31 de julio de ese año fue promovido al empleo de Médico Segundo y destinado al Segundo Batallón del Regimiento de Infantería de África $n^{\circ} 68$, al que se incorporó en Melilla el 29 de agosto, marchando el 30 al campamento de Tifasor a las órdenes de teniente coronel Carlos Cos-Gayón Gómez.

Bosch estuvo en activo en el Ejército hasta diciembre del año 1924, y permaneció en la reserva hasta 1933. Gran parte de ese tiempo lo pasó en África, salvo la etapa comprendida entre 1917 y agosto de 1921. El 9 de mayo de 1917 se inscribió en el Colegio de Médicos de Madrid como especialista en Electromedicina, y a partir de entonces los destinos fueron Villaviciosa de 
Odón, Cartagena, Murcia y Jaca (Huesca). En esos cuatro años se dedicó al diseño de aparatos médicos y patentó varios, entre ellos un botiquín de urgencia (1918), un hospital de campaña (1919), trócares para función ósea, ducha ocular y el llamado Radiozono (1919).

En agosto de 1921, tras los sucesos de Annual y Monte Arruit, fue destinado al Rif y allí permaneció hasta 1924. El 26 de septiembre de este último año fue incluido, como capitán médico, en la lista de militares que no podían solicitar destino voluntario por faltarle menos de seis meses para ser destinado con carácter forzoso al territorio de África.

En 1924 comenzó el ejercicio de la Medicina privada en el número 4 de la calle Sagasta de Madrid, especializándose en Radiología. En el expediente del Colegio de Médicos de Madrid figura un documento fechado el 5 de noviembre de 1930 donde se indica que fue demandado por dispensar tóxicos a los pacientes, denuncia que no prosperó. En esos años volvió a diseñar y patentar aparatos y herramientas de trabajo, entre ellos una ambulancia (1930). De su faceta creativa resultaron también dos aparatos caseros: una lavadora de émbolo y un modelo de fregona. En Ondara, localidad que visitaba habitualmente por ser la villa natal de su padre, montó con José Llorens Bosch una fábrica de material quirúrgico.

Durante la Segunda República fue Secretario de la Asamblea para la creación de la Mutua Obrero-Sanitaria del sindicato Confederación Nacional de Trabajadores (CNT) de Madrid. Entre 1934 y 1936 fue Secretario de Actas de la Sociedad Española de Radiología, bajo la presidencia del doctor Julio Orensanz Tarongi. Al estallar la Guerra Civil prestó servicio en Madrid y fue nombrado director del Instituto de Traumatología a finales de 1936, después fue destinado a Alicante, donde en agosto de 1937 fue Jefe de Servicios de Fisioterapia en el Hospital Militar de la ciudad. El Comité Provincial de la CNT en Alicante le propuso el 20 de agosto de 1938 para el empleo de Comandante. Al terminar la contienda fue depurado y encarcelado en la plaza de toros de Valencia, de donde salió gracias a la intervención de sus hermanos.

El Colegio de Médicos de Alicante tramitó la depuración sin sanción (colegiado $n^{\circ} 736$ ) desde el 1 de diciembre de 1942, si bien en julio ya había sido destinado como Médico de Asistencia Pública Domiciliaria a la localidad cordobesa de Bélmez, donde permaneció hasta 1946. El 27 de junio de 1945 solicitó la reincorporación al Colegio de Médicos de Madrid, y en 1946 instaló su domicilio en el número 36 de la calle Alber- to Aguilera y retomó el trabajo en la clínica de Sagasta. Falleció en Madrid el 16 de mayo de 1978 a los 93 años.

\section{Tratamiento documental del fondo: metodología y resultados}

Los documentos recuperados son 509 negativos en soporte cristal y formato $10 \times 15 \mathrm{~cm}$, distribuidos en 32 cajas (Tabla I). Un tercio están relacionados con su estancia en África y por tanto representan la vida cotidiana de los soldados, desde los momentos de descanso hasta las incursiones en territorio hostil, más algunas vistas espectaculares de Xauen. Las tomas verticales son 23 y el resto horizontales, prácticamente todas están numeradas mediante incisión en la emulsión, lo que permite saber que el archivo constaba al menos de 1.474 originales, aunque sin duda fueron más. De todos ellos, los cuatrocientos primeros, salvo excepciones, se corresponden con su estancia en el norte de Marruecos durante la guerra, y de estos se conservan 325 originales.

\begin{tabular}{cc|cc}
\hline Caja & Placas & Caja & Placas \\
\hline 1 & 16 & 17 & 09 \\
\hline 2 & 17 & 18 & 19 \\
\hline 3 & 11 & 19 & 18 \\
\hline 4 & 17 & 20 & 17 \\
\hline 5 & 16 & 21 & 13 \\
\hline 6 & 17 & 22 & 18 \\
\hline 7 & 19 & 23 & 17 \\
\hline 8 & 17 & 24 & 21 \\
\hline 9 & 17 & 25 & 22 \\
\hline 10 & 18 & 26 & 16 \\
\hline 11 & 17 & 27 & 17 \\
\hline 12 & 13 & 28 & 16 \\
\hline 13 & 12 & 29 & 13 \\
\hline 14 & 18 & 30 & 15 \\
\hline 15 & 16 & 31 & 13 \\
\hline 16 & 14 & 32 & 10 \\
\hline Total & & \multicolumn{2}{c}{509} \\
\hline \multicolumn{2}{r}{ Tabla l. Negativos } \\
\hline
\end{tabular}

En el análisis del conjunto se ha trabajado en una doble vía; en primer lugar en la autoría de las imágenes, desconocida en el momento en que fueron adquiridas las fotografías; y en un segundo término en los contenidos. Como se ha indicado casi todas las placas se encontraban dentro de cajas, desordenadas con respecto a la numeración, excepto cuatro paquetes envueltos en papel. En uno de los envoltorios aparecía el nombre J. Bosch y una calle de Madrid: Alberto Aguilera. 
Revisadas todas las placas ante un negatoscopio, se procedió a la reproducción de las placas en el tablero de luz con cámara Cannon Eos 7D, y objetivo macro de alta definición con luminosidad 2.8, obteniendo ficheros digitales en bruto y en negativo. La colección se duplicó para obtener positivos tratados con el programa Photoshop, generando una segunda colección que a su vez fue duplicada para llevar a cabo una ordenación numérica, con una carpeta reservada a los negativos sin número (104 ficheros), tarea que permitió identificar por similitud de contenidos una parte de éstos.

Por lo que se refiere al análisis documental, se ha llevado a cabo diseñando una ficha de trabajo con campos extraídos de las normas ISAD (G): autor, título, fecha, descriptores (onomásticos, geográficos y temáticos), conservación y observación. En este último se han anotado referencias específicas, tales como el vestuario, la situación anímica de los soldados, el momento de la contienda, etc. Dado que el formato, soporte y características técnicas de todas las placas es el mismo $(10 \times 15 \mathrm{~cm}$; vidrio, blanco y negro), se decidió no incluir estos campos puesto que la referencia es genérica en la descrip- ción del fondo. Para la identificación se ha tenido en cuenta el expediente militar de Bosch, donde se detallan los lugares en los que estuvo destinado. Solo en 22 casos se indica claramente la localidad: Zeluán (1) y Xauen (21).

Se han analizado todas las fotografías sobre la guerra de África para obtener descriptores con el fin de recuperar la información relacionada con esta materia. Como resultado se han obtenidos 1098 palabras clave normalizadas, con una media de cinco por placa, que se relacionan y adjuntan en la Tabla II y que se comprenden en el siguiente conjunto temático: Agricultura, Armamento, Comercio, Construcción, Etnografía, Ganadería, Geografía, Medicina, Militares, Obras públicas, Religión, Transportes, y Vegetación.

Dentro del grupo Varia se incluyen aquellas fotografías que son únicas y singulares por la materia; como por ejemplo: juegos, libros, lectura o cortejo fúnebre. Jorge Bosch Díaz aparece en 187 fotografías, bien solo o en grupo. El mayor número de fotos tiene como palabra clave "militares" (264 en grupo y 39 individuales), seguido de "Tiendas de campaña" (49), "Moros" (46) y "Caballos" (60).

\begin{tabular}{|c|c|c|c|c|c|c|c|}
\hline Abrevadero & 1 & Cañones & 13 & Ganado & 3 & Puertas & 12 \\
\hline Alcazaba & 2 & Cargamento & 13 & Guitarras & 2 & Rancho & 6 \\
\hline Alforja & 1 & Carreteras & 8 & Herramientas & 1 & Recolección & 1 \\
\hline Altar & 2 & Carros & 11 & Hospital & 1 & Regimiento 40 & 1 \\
\hline Arado & 1 & Carroza fúnebre & 1 & Instrumento musical & 2 & Regimiento 68 & 1 \\
\hline Árboles & 14 & Casas & 39 & Instrumento médico & 1 & Regimiento Badajoz & 3 \\
\hline Arbustos & 5 & Cereales & 1 & Juego salto cabrilla & 1 & Río & 16 \\
\hline Arcos & 8 & Coches & 17 & Lana & 1 & Sables & 3 \\
\hline Armamento & 7 & Colina & 12 & Lectura & 2 & Sacerdote & 1 \\
\hline Autobús & 1 & Comercio (tienda) & 5 & Libros & 3 & Sacos de arena & 6 \\
\hline Banda militar & 2 & Construcción & 8 & Maniobras & 1 & Sillas & 19 \\
\hline Bandera & 1 & Convoy & 2 & Medicamentos & 3 & Sombras & 6 \\
\hline Barcos & 1 & Cortejo fúnebre & 1 & Mercado & 2 & Té & 2 \\
\hline Barracones & 12 & Cruz Roja & 9 & Militares (solos) & 39 & Tendido eléctrico & 2 \\
\hline Barriles & 8 & Desfile & 2 & Militares (grupos) & 264 & Tienda de campaña & 49 \\
\hline Bebidas & 9 & Documentos & 9 & Minarete & 2 & Tocadiscos & 1 \\
\hline Botiquín & 3 & Domador serpientes & 1 & Misa & 2 & Torre & 2 \\
\hline Burro & 2 & Edificios & 27 & Montañas & 19 & Torreón & 1 \\
\hline Caballos & 61 & Enfermería & 4 & Moros & 46 & Tren & 9 \\
\hline Cactus & 4 & Entierro & 2 & Muralla & 32 & Vallas & 11 \\
\hline Calles & 18 & Equipo médico & 1 & Niños & 38 & Valle & 22 \\
\hline Camellos & 3 & Escuela primaria & 1 & Oveja & 2 & Vegetación & 10 \\
\hline Camillas & 2 & Explosión & 2 & Panadería & 1 & Ventana & 3 \\
\hline Camino & 13 & Farmacia militar & 3 & Patios & 6 & Vista aérea & 5 \\
\hline Camiones & 7 & Formación militar & 11 & Perros & 7 & Zoco & 3 \\
\hline Campamento & 22 & Frascos de botica & 3 & Procesión & 1 & & \\
\hline Cantina & 2 & Fuentes & 2 & Puentes & 10 & Total & 1098 \\
\hline
\end{tabular}

Tabla II. Descriptores Guerra de África 
A partir de los ficheros con las fotos en positivo se han realizado mosaicos para la selección de las ilustraciones al texto, de acuerdo a dos criterios: la calidad de imagen y la diversidad temática para dejar representados todos los contenidos: sujetos, paisajes, espacios exteriores e interiores, objetos, acciones, animales y escenarios especiales.

Desde el punto de vista estrictamente fotográfico, hemos de señalar que la mayor parte de las placas son de gran calidad, y que las escenas fueron preparadas en numerosos casos, lo que indica un conocimiento de la materia. Los retratos de grupo son un ejemplo, y los tomados a los oficiales con la instalación de fondos así lo confirman. Otra referencia que avala la condición de experto amateur son las preciosas vistas de Xauen (21 tomas), que descubren al autor como pictorialista al captar paisajes y tipos en su ambiente.

Queda por realizar un exhaustivo trabajo en lo que se refiere a la identificación detallada de lugares y personajes, lo que implica la necesidad de invertir tiempo en la revisión de prensa en las hemerotecas.

\section{Conclusiones}

Del estudio de las fotografías de Bosch Díaz se concluye que se trata de un fondo de gran interés para la historia de la guerra de África, en especial por la variedad de contenidos, también por la muestra de la actividad médica, y para la historia de la fotografía por el descubrimiento de un nuevo conjunto de negativos fechados en el primer tercio del siglo $\mathrm{XX}$.

Dada la situación en que se encontraron las placas de cristal y las dificultades para recuperarlas, considerando además la oferta de documentos similares en los portales de Internet, se concluye que es necesario cubrir el vacío institucional en cuanto a las actuaciones para la preservación y recuperación mediante un protocolo específico que pretenda evitar la pérdida o destrucción de los fondos y colecciones.

Por lo que respecta al análisis, queda de manifiesto que las fotografías de aficionados tienen idéntico valor que los de profesionales en lo que se refiere al documento en forma y fondo, es decir en su soporte y contenido, ya que generalmente presentan la intrahistoria que completa el hecho noticiable, es decir que contextualizan la información.

De manera específica, este conjunto documental es un referente para conocer los distintos lugares donde estuvo destinado el autor, su trabajo, la relación con el resto de militares, y la vida cotidiana en el ejército, incluidos aspectos específicos como el armamento, los uniformes o el mobiliario. Un aspecto fundamental es la concesión de permisos para obtener este tipo de imágenes, generalmente vetadas si tenemos en cuenta que se tomaron en los años en que se produjeron los mayores enfrentamientos.

Por último, la difusión de los documentos posibilita nuevas vías de investigación en varias materias: historia de España, guerra de África, historia de la fotografía, fotografía médica y patrimonio fotográfico

\section{Apéndice: Selección de fotografías}

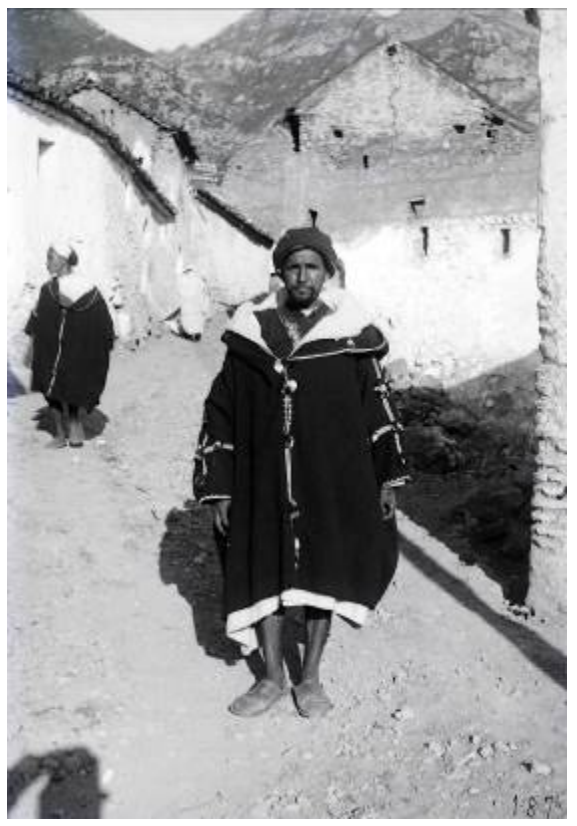

Figura 1. Tipo de Xauen (187 C-10)

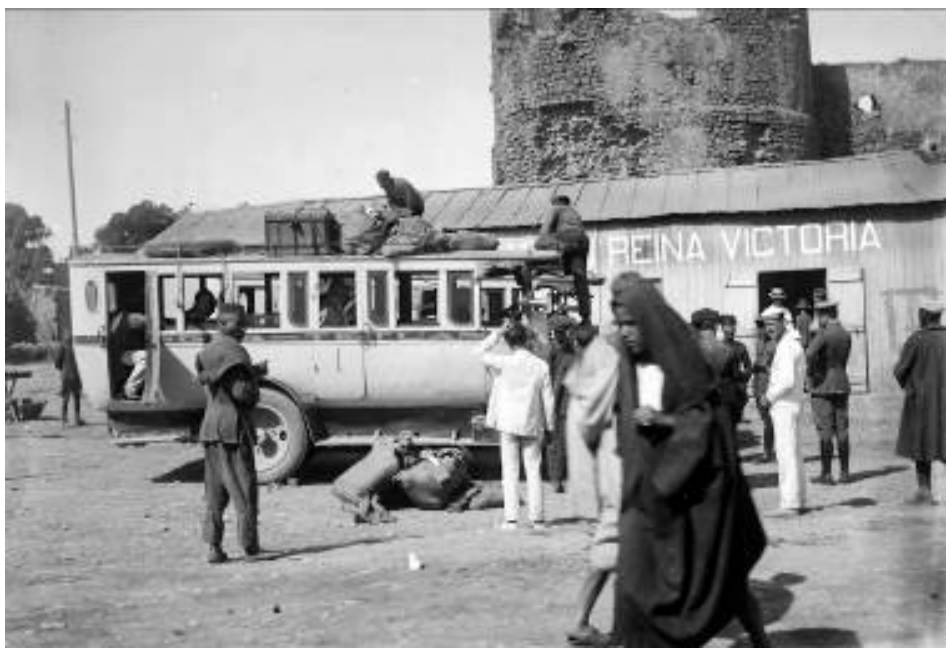

Figura 2. Autobús de línea (C-8) 


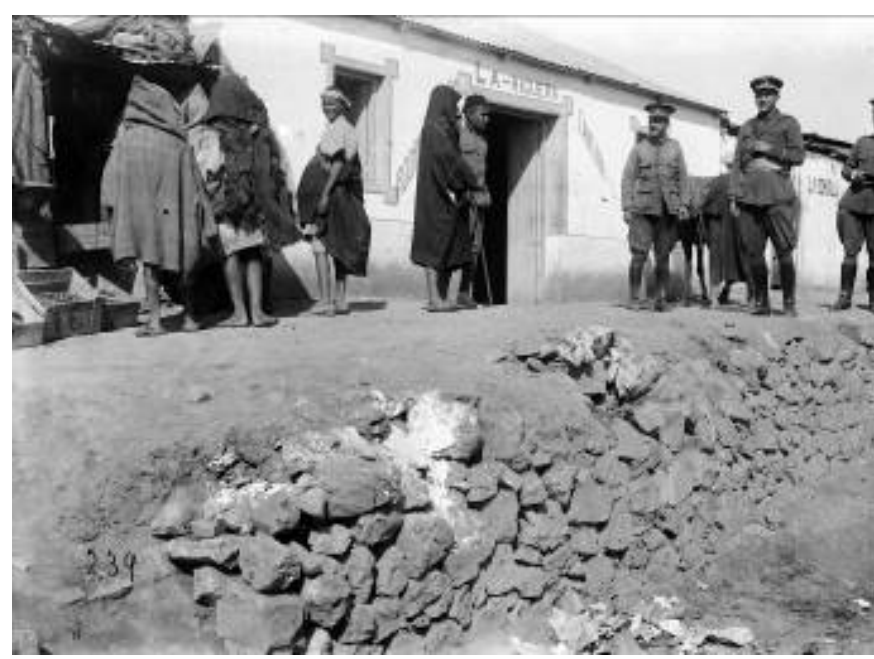

Figura 3. Cantina La Higuera (239 C-10)

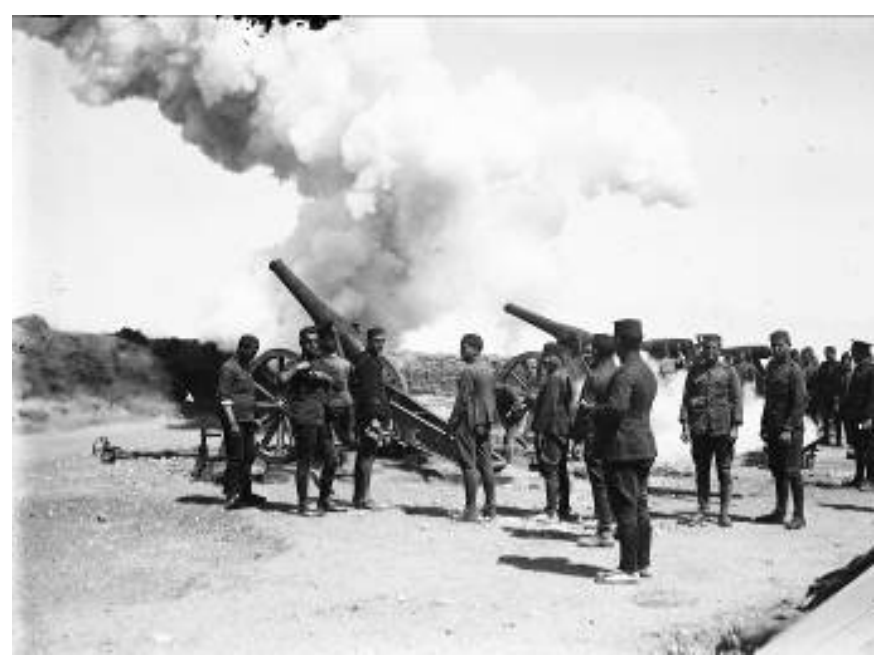

Figura 4. Disparando los cañones (263 C-6)

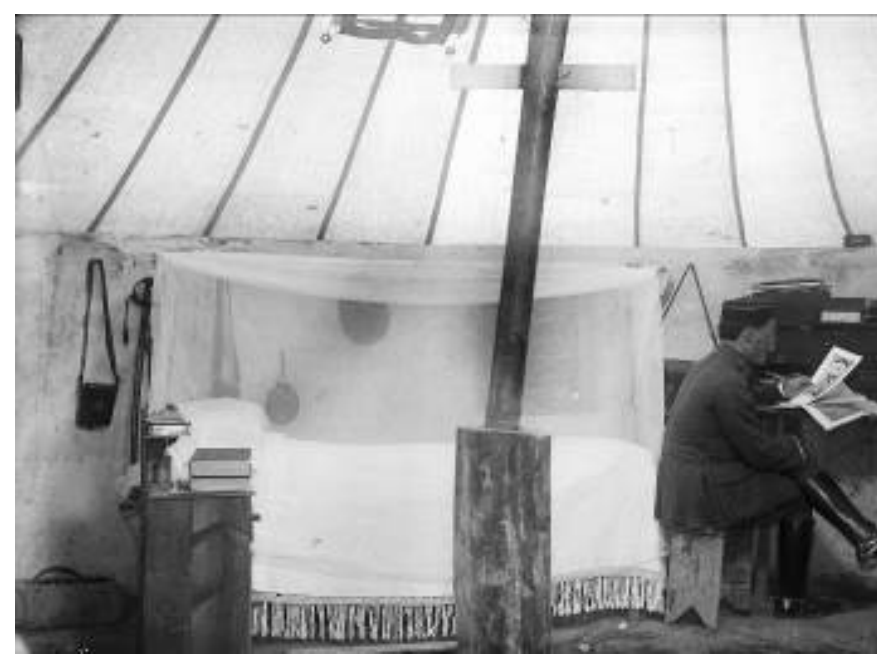

Figura 5. El capitán Bosch en su tienda (106 C-5)

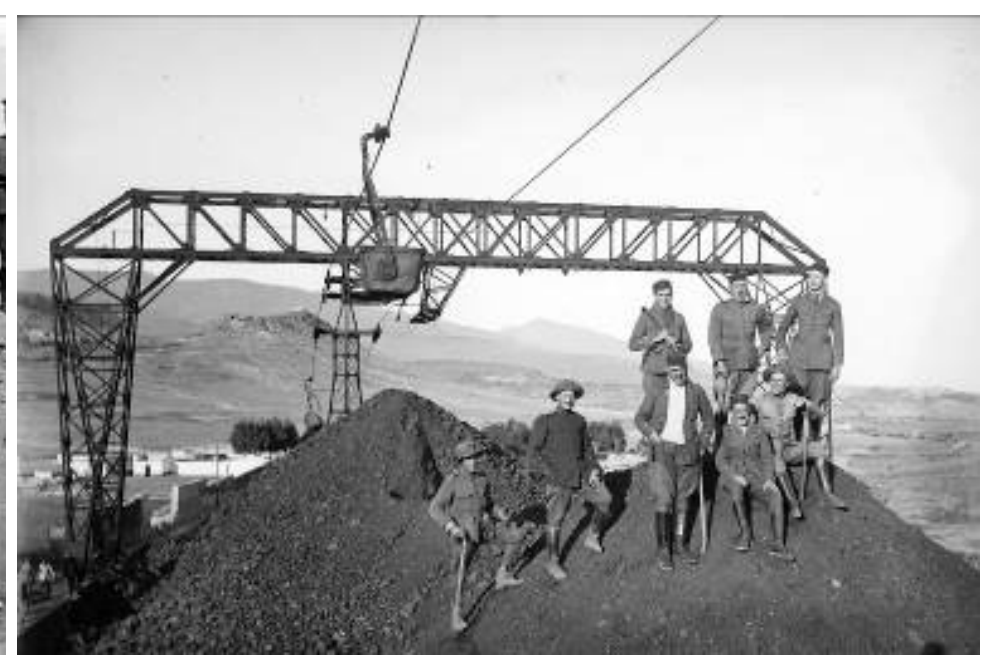

Figura 6. Minas del Rif (C-9)

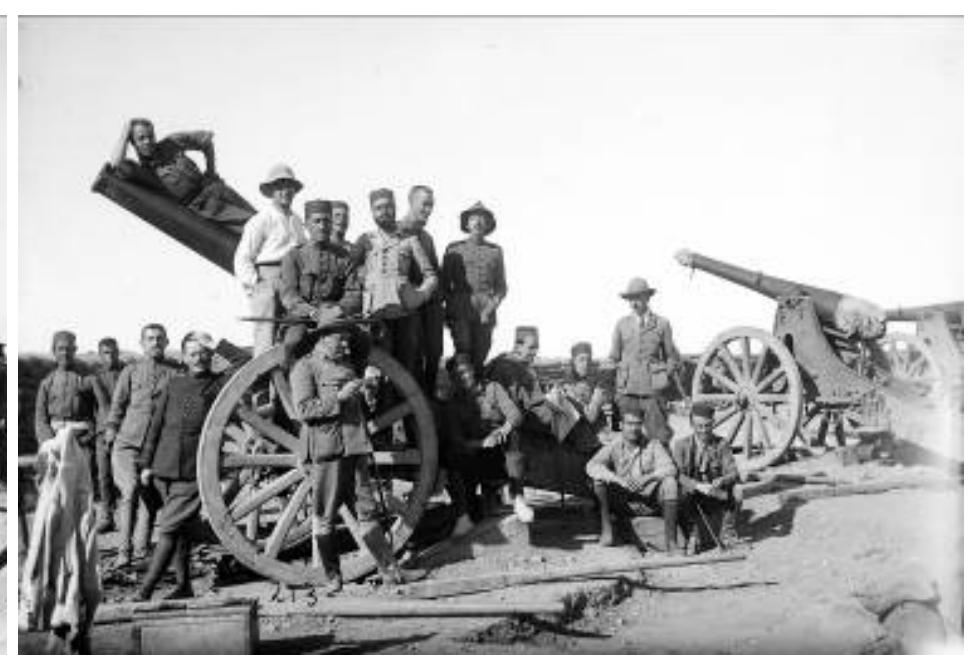

Figura 7. Posando ante los cañones (213 C-9)

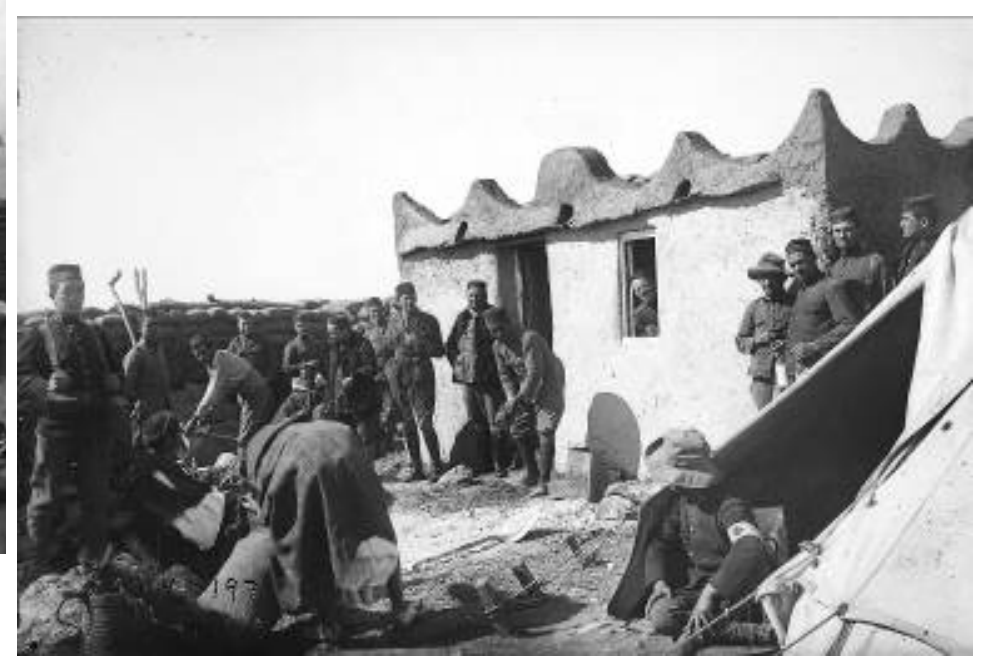

Figura 8. Posición (197 C-27) 


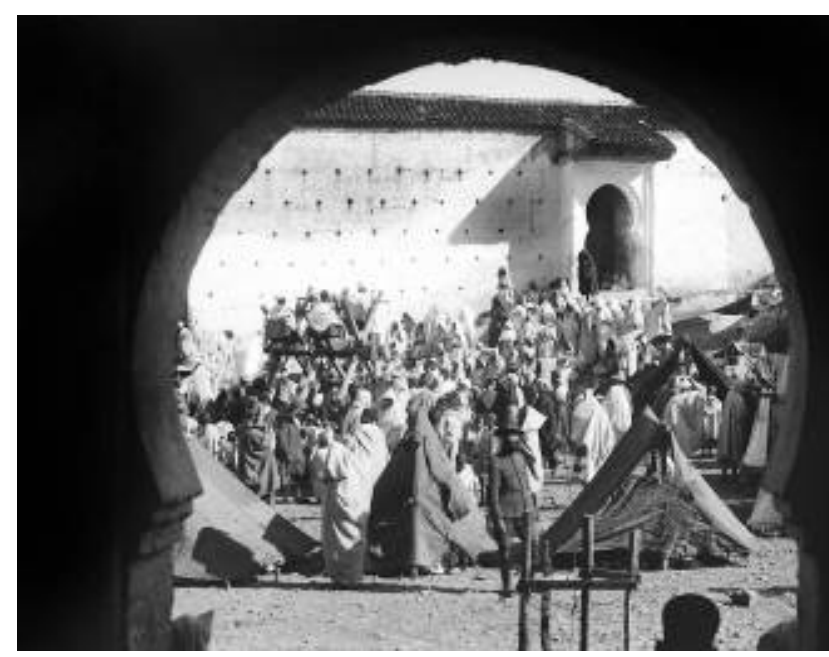

Figura 9. Xauen (170 C-18)

\section{Referencias}

Almela Cots, Joan M. (2015). Valeriano Bosch (Ondara 1853-Valencia 1931): Vida, obra i família d' un general al servei de l'administració militar. Ondara: Edicions 96.

Boadas, Joan; Casellas, Lluis-Esteve; Suquet, M. Àngels (2001). Manual para la gestión de fondos y colecciones fotográficas. Barcelona: CCG. Centre de Ricerca i Difusió de la Imatge.

Castillo Cáceres, Fernando; Cabezón Pérez, Pilar (2006). La vida cotidiana en el Ejército, 1855-1925. Fotografías del Archivo General Militar de Madrid. Madrid: Ministerio de Defensa.

Chumillas, Rosa (2015). Plan Nacional de conservación de la fotografía. Madrid: Ministerio de Defensa.

Gómez Barceló, José Luis (2007). Fotografía española en Marruecos: realidades soñadas, ensoñaciones recreadas. // Mélanges Casa de Velázquez. 37:1, 56-81.

Gómez Barceló, José Luis (2005). Tiempo de guerra, imágenes de paz. Iconografía militar de Bartolomé Ros. Madrid: Ministerio de Defensa.
ICA (2000). ISAD (G): general International Standard Archival Description. Ottawa: International Council on $\mathrm{Ar}$ chives.

Kossoy, Boris (2014). Lo efímero y lo perpetuo en la imagen fotográfica. Madrid: Cátedra.

Lavédrine, Bertrand (2010). (Re)conocer y conservar las fotografías antiguas. París: CTHS.

Mestre, Jordi (2004). Identificación y conservación de fotografías. Gijón: Trea.

Olivera Zaldua, María (2014). La fotografía en el Protectorado español. Los fondos fotográficos del Legado Fernando Valderrama en la Biblioteca Islámica (Biblioteca AECID). // Revista General de Información y Documentación. 24:1, 155-182.

Salvador Benítez, Antonia; Coord. (2015). Patrimonio fotográfico. De la visibilidad a la gestión. Gijón: Trea.

Sánchez Vigil, Juan Miguel; Olivera Zaldua, María (2012). Documentación fotográfica. Cuaderno de Trabajo. Madrid: Universidad Complutense de Madrid.

Seco Serrano, Carlos (1995). El plano inclinado hacia la dictadura, 1922-1923 // La España de Alfonso XIII. EI estado y la política (1902-1931). Madrid: Espasa. Historia de España de Menéndez Pidal, XXXVIII, vol. 2, 65-82

Silva, Lorenzo (2013). Siete ciudades en África: Historia del Marruecos español Sevilla: Fundación José Manuel Lara

Silva, Lorenzo (2001). Del Rif al Yebala. Viaje al sueño y la pesadilla de Marruecos. Barcelona: Destino.

Tuñon de Lara, Manuel (1984). Estructuras sociales, 18981931. // Los comienzos del siglo XX. La población, la economía, la sociedad. Madrid: Espasa. Historia de España de Menéndez Pidal, XXXVII, 653-655.

Tussell, Javier (1995). La solución al embrollo marroquí (1923-1925). // La España de Alfonso XIII. El estado y la política (1902-1931). Madrid: Espasa. Historia de España de Menéndez Pidal. XXXVIII: 2, 267-345.

Valle Gastaminza, Félix del, Coord. (1999). Manual de documentación fotográfica. Madrid: Síntesis.

Enviado: 2017-04-19. Segunda versión: 2017-06-24. Aceptado: 2017-09-04. 
